\title{
Alterations in cerebral blood flow produced by hypotension: a comparison of methods
}

\author{
FRANCIS W. GAMACHE AND GEORGE M. DOLD \\ From the Laboratory of Perinatal Physiology and Neural Control,, National Institute of Neurological \\ Diseases and Stroke, National Institutes of Health, United States Public Health Service, \\ Department of Health, Education, and Welfare, Bethesda, Maryland 20014, U.S.A.
}

SYNOPSIS Alterations in cerebral blood flow produced by controlled episodes of hypotension were studied in 12 juvenile monkeys using a thermocouple technique. The qualitative changes observed agreed closely with those obtained from an earlier study employing $\left[{ }^{14} \mathrm{C}\right]$ antipyrine autoradiographic methods. The present study extends the validity of the earlier antipyrine investigations by means of the continuous recording. The advantages and disadvantages of the thermocouple technique are examined.

Determinations of simultaneous changes in blood flow to discrete neuroanatomical structures (L-CBF) associated with regulated episodes of hypotension have been carried out for the first time just recently (Gamache et al., 1975b). L-CBF determinations which employ the $\left[{ }^{14} \mathrm{C}\right]-$ antipyrine modification of the autoradiographic method for measuring L-CBF (Sokoloff, 1961; Reivich, 1972), as in the above study, do not permit serial determinations of blood flow in the same animal. They require large numbers of animals for study and very meticulous, laborious analysis. However, the antipyrine method offers the advantage of accurate quantitation of blood flow to specific neuroanatomical structures for any chosen instant of time. We were interested in discovering whether we could reproduce the general results of our earlier studies with a less sophisticated technique that would monitor the continuous dynamic record of tissue perfusion in the same animal, and one that might also offer clinical application because of its simplicity.

The variety of methods employed clinically and experimentally to measure cerebral blood flow (CBF) speaks for the lack of superiority of one technique above all others. Nevertheless, we decided to employ (and slightly modify) the familiar method of Gibbs (1933) to record changes in cortical blood flow associated with episodes of hypotension. The present study indeed reproduces and complements qualitatively the impressions obtained by the earlier antipyrine investigations, but extends the validity of those studies by virtue of the continuous recording. However, the difficulties of quantitating CBF and the ambiguous results produced by probe-tissue interactions with the use of the thermocouple technique are stressed.

\section{METHODS}

Twelve juvenile monkeys (Macaca mulatta) weighing $3.2-6.0 \mathrm{~kg}$ were used. Each was anaesthetized with pentobarbitone, $30 \mathrm{mg} / \mathrm{kg}$ intravenously, and prepared for study as described earlier (Gamache $e t$ al., 1975a), including mechanical ventilation. Control values for physiological parameters were established for 60 minutes before beginning the experiments. Mean arterial blood pressure was abruptly lowered to $25 \mathrm{mmHg}$ with a trimetaphan infusion $(2 \mathrm{mg} / \mathrm{ml})$ and maintained at this level for $\mathbf{3 0}$ minutes. Pressure was then returned to and maintained at prehypotensive levels with a phenylephrine drip $(0.02 \mathrm{mg} / \mathrm{ml})$ (Gamache et al., 1975a). Arterial gas tension and $\mathrm{pH}$ were maintained at all times at pre-insult levels.

MEASUREMENT OF CBF Thermocouple probe construction Two $80 \mathrm{~mm}$ length pieces of $125 \mu \mathrm{m}$ copper and two of $125 \mu \mathrm{m}$ constantan were joined by an arc-weld (with a mercury bath) and then enamelled 


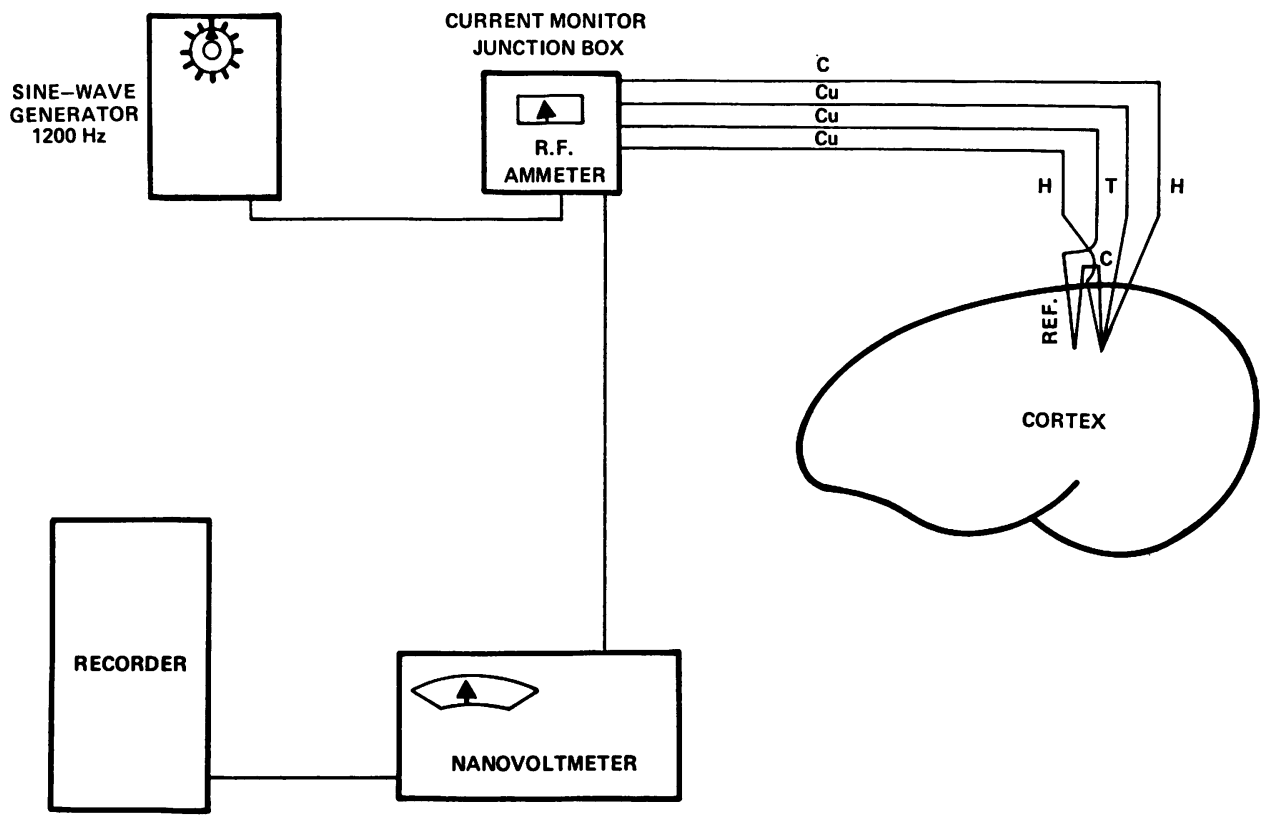

FIG. 1 Diagram of the apparatus used to record changes in cerebral blood flow (see text).

$(5 \mu \mathrm{m})$. The wire probe was inserted in a $70 \mathrm{~mm}$ length of 19 gauge stainless steel tubing, exposing $1 \mathrm{~mm}$ of the probe tip - that is, the arc-weld-at one end and the free copper, constantan wires at the opposite end. A temperature reference electrode (reference) was similarly constructed (Fig. 1).

BLOOD FLOW MEASURING APPARATUS In order to avoid error introduced by changes in body temperature, a thermocouple-temperature reference system was employed (Gibbs, 1933; Norcross, 1938; Grayson, 1952). The two probes were mounted parallel but $5 \mathrm{~mm}$ apart from one another on a parallel clamp with phenolic insulated faces. Probes were connected to the recording system as indicated in Fig. 1. During the measurements a constant (approximately) $165 \mathrm{~mA}, 1.2 \mathrm{kHz}$ current was applied to heat the copper-constantan joint (hot junction). A Hewlett-Packard 201C audio-oscillator furnished the current through a step-down transformer in the current monitor box. The thermocouple R.F.-ammeter in the current monitor box was not wave form or frequency sensitive. The potential difference sensed at the thermocouple tip and balanced for changes in body temperature via the reference electrode was continuously monitored by a Keithley model 148 Nanovoltmeter and recorded on a Sanborn model 7700 recorder. Before and after each experiment, the thermocouple was calibrated for thermal conductivity with $165 \mathrm{~mA}, 1.2 \mathrm{kHz}$ signals in still water at $0^{\circ} \mathrm{C}$ to verify a $39 \mu \mathrm{V}$ voltage change associated with a $1{ }^{\circ} \mathrm{C}$ temperature change. Thermocouple recordings were made from all brains after death or the killing of the animals.

The theoretical bases for measuring flow past a heated tip are well known (Norcross, 1938; Grayson, 1952). A major source of error using this technique has been the influence of changes in body temperature on temperature changes observed by the thermocouple (intended to relate strictly to alterations in blood flow). However, the current set up in a simple temperature monitoring device and appropriately connected to the flow probe can balance this effect of body temperature, as has been discussed elsewhere (Norcross, 1938; Grayson, 1952). Thus, in the present study, as in others (Gibbs, 1933; Carter et al., 1973), changes in blood flow are described as changes in potential (voltage) as measured directly at the probe, since flow varies linearly with voltage (Grayson, 1952).

The thermocouple-reference assembly was lowered through a $7 \mathrm{~mm}$ burr hole $3 \mathrm{~mm}$ into the superior one-third of the right postcentral gyrus with a micrometer assembly as described earlier (Gamache et al., 1975a). This satisfied the requirement for satisfactory recording (a $1.5 \mathrm{~mm}$ or greater tissue 


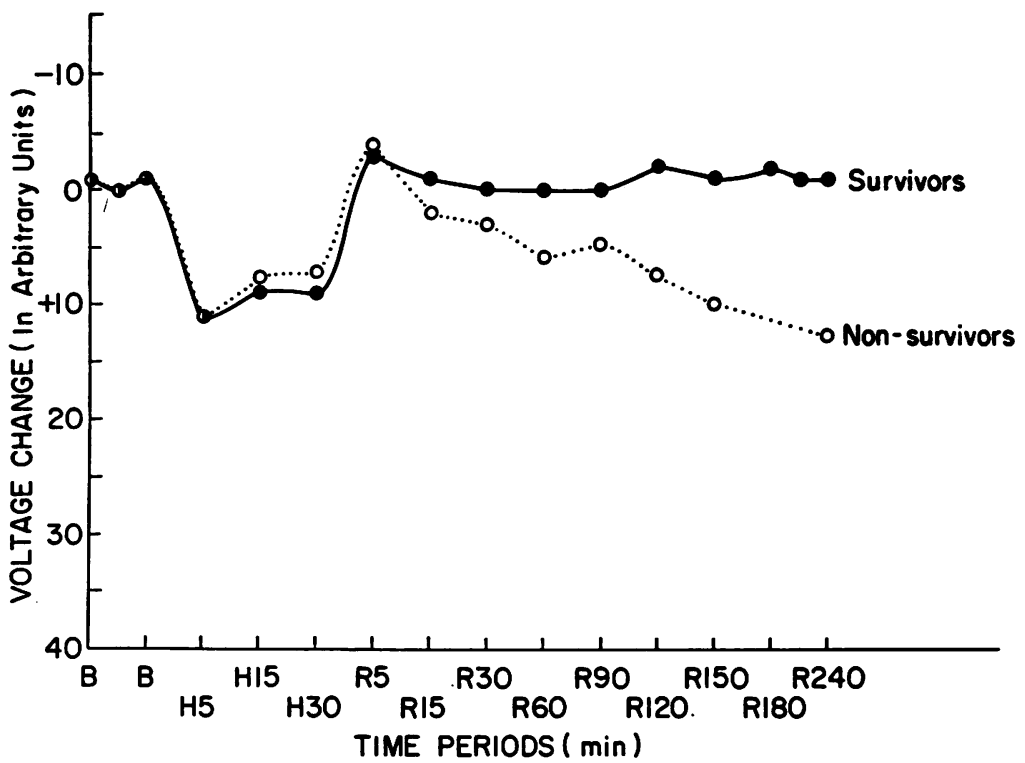

FIG. 2 Changes in mean cortical voltage (in arbitrary units) are graphed against time. A mean voltage (to describe the small oscillation in voltage) for each animal at each time point was recorded. $\mathrm{B}, \mathrm{H}$, and $\mathrm{R}$ refer to (groups) mean values obtained during baseline, hypotension, and recovery periods respectively. Plotted values are mean values for five survivors and seven non-survivors. SES ranged from 1-3 (arbitrary units) for each group for the different time periods studied.

cuff around the probe tip) described by others (Grayson, 1952). The reference probe was placed upstream relative to the thermocouple, as determined by simple inspection of the arterial tree in the involved area. The hole was filled with bone wax and the assembly left in place throughout the experiment. Final electrode position was later verified at necropsy.

Single channels of the electroencephalogram (parieto-occipital) and electrocardiogram (lead II) were recorded from subcutaneous electrodes (Gamache et al., 1975a). A radiant heat shield maintained body temperature (monitored by skin and rectal probes) at $37.5 \pm 0.5^{\circ} \mathrm{C}$ during the entire study.

The techniques utilized to bring about and maintain hypotension and the care rendered after hypotension were as noted above and earlier described (Gamache et al., 1975a). During the recovery period, intravenous furosemide $(5-10 \mathrm{mg}$ single intravenous injections) and urea $(20-75 \mathrm{ml}$ infusions) were administered to treat brain swelling in three animals in which cortex had begun to bulge through the burr hole. Surviving animals were killed at two to three weeks; neuropathological specimens were prepared after saline/formalin perfusion as before (Gamache et al., 1975a). These surviving animals correlated with those animals in the antipyrine study which were not neurologically depressed at the time when they were killed for CBF determination; nonsurviving animals corresponded to neurologically depressed animals in the antipyrine study.

\section{RESULTS}

The physiological and neuropathological changes produced by 30 minute hypotensive episodes followed the same trends observed and described in previous studies (see Gamache et al., 1975a, $\mathrm{b}$ for a detailed description) and are summarized in the Table.

THERMOCOUPLE RESULTS Voltage varied slightly around a baseline, arbitrarily established at approximately zero for each separate experiment during the 60 minute control period. After five minutes of hypotension, voltage increased significantly ( $\mathrm{P}<0.05$ by the paired $t$ test) from control values, and was almost significantly 
TABLE

SUMMARY OF PHYSIOLOGICAL AND NEUROPATHOLOGICAL FINDINGS

\begin{tabular}{|c|c|c|c|c|c|c|c|c|c|c|c|}
\hline & & $E C G$ & $\begin{array}{l}\text { Heart } \\
\text { rate } \\
(\% \\
\text { decreases })\end{array}$ & & Respirations & & $\begin{array}{l}\text { Cortex } \\
\text { bulging* }\end{array}$ & & $\begin{array}{l}\text { Clinical } \\
\text { status }\end{array}$ & & $\begin{array}{l}\text { Post-mortem } \\
\text { examination }\end{array}$ \\
\hline $\begin{array}{l}\text { Survivors: } \\
\text { (5) }\end{array}$ & $\begin{array}{l}\text { (4) } \\
\text { (1) }\end{array}$ & $\begin{array}{l}\text { Mild ST } \\
\text { or T wave } \\
\text { changes } \\
\text { No change }\end{array}$ & (5) 20.33 & (5) & $\begin{array}{l}\text { Spontaneous and } \\
\text { effective }\end{array}$ & (5) & No change & (5) & No change & (5) & No abnormality \\
\hline $\begin{array}{l}\text { Non-survivors: } \\
\text { (7) }\end{array}$ & $\begin{array}{l}\text { (5) } \\
\text { (2) }\end{array}$ & $\begin{array}{l}\text { Mild ST } \\
\text { or T wave } \\
\text { changes } \\
\text { No change }\end{array}$ & (7) 20.33 & $\begin{array}{l}\text { (4) } \\
\text { (3) }\end{array}$ & $\begin{array}{l}\text { Spontaneous but } \\
\text { not effective } \\
\text { Apnoeic }\end{array}$ & $\begin{array}{l}\text { (3) } \\
\text { (4) }\end{array}$ & $\begin{array}{l}\text { No change } \\
\text { Marked }\end{array}$ & (7) & Variable & $\begin{array}{l}(4) \\
(3)\end{array}$ & $\begin{array}{l}\text { No abnormality } \\
\text { Mild to } \\
\text { moderate } \\
\text { brain } \\
\text { swelling }\end{array}$ \\
\hline
\end{tabular}

* Cortex bulging against burr hole for thermocouple probes.

higher $(\mathrm{P} \approx 0.1)$ than the values recorded at 15 and 30 minutes of hypotension. The voltage values at 15 and 30 minutes were significantly higher $(\mathrm{P}<0.05)$ than control levels, but not significantly different from one another $(P \gg 0.1)$. Values for survivors and non-survivors did not differ significantly from one another before or during hypotension (using the $t$ test evaluating differences between independent means) (Fig. 2).

When arterial blood pressure was restored to pre-hypotensive levels, five minutes into recovery, voltage was slightly but not significantly lower than the values observed during the control period $(\mathrm{P} \approx 0.1)$. Thereafter voltage oscillated above and below baseline for the survivors; at no time were values significantly different from controls $(\mathrm{P} \gg 0.1)$. The behaviour of the voltage trend for non-survivors was different. For these animals, voltage initially returned to near normal levels and was not significantly different from control values until 60 minutes of recovery, beyond which voltage was consistently above baseline $(\mathrm{P}<0.05)$ (Fig. 2). The voltage trends for survivors and non-survivors were slightly different $(\mathrm{P}=0.1)$ at 60 minutes of recovery; beyond 120 minutes of recovery they were frankly different $(\mathrm{P}<0.05)$.

\section{DISCUSSION}

From earlier studies with the same model used in the present study (Gamache et al., 1975b), changes in blood flow to parietal cortex were found to be representative of changes in flow to the cortices in general. Flow levels were lowest at five minutes of hypotension, and slightly but significantly higher between 15 and 30 minutes, despite a constant mean arterial blood pressure. After the return of blood pressure to prehypotensive levels cerebral blood flow in general was above control levels. During later stages of recovery, near normal blood flow correlated with a reactive neurological status, whereas blood flow levels of $50-70 \%$ of controls correlated with depressed neurological recovery (Gamache et al., 1975b). The data from the present study (Fig. 2) agree closely. There are, however, some noteworthy differences.

In the present study, voltage after five minutes of hypotension was slightly but not quite significantly different (versus frankly different (Gamache et al., 1975b)) from the 15 and 30 minute levels. Carter and Atkinson (1973), using similar methods, observed that CBF to cortex was lowest after abrupt onset hypotension; however, their finding is inconclusive, since they failed to maintain a constant blood pressure level and did not make allowances for temperature changes in their study. The individual variability in recorded voltages in this study, secondary to motions of the brain associated with mechanical ventilation-that is, voltage oscillation-was necessarily associated with sizeable standard errors (about a mean); this bias carried over to the statistical correlations. This most likely accounts for the statistical differences - that is, $\mathrm{P}=0.1$ vs $\mathrm{P}<0.05$-observed between the present and the earlier (Gamache et al., 1975b) studies 
for the time point of five minutes of hypotension. Similar explanations may be made for the statistical differences observed between this and the earlier (Gamache et al., 1975b) study regarding blood flow five minutes into recovery. There are no other studies with which to compare our results on this point, however. In any case, knowledge of the characteristics of the changes in cerebral blood flow produced by hypotension has particular clinical relevance, where episodes of controlled hypotension are used in surgery, and where one needs to know at what time CBF is dangerously low or injuriously high.

The present study confirms the impressions of CBF activity in the post-hypotensive period as obtained from indirect (impedance (Gamache $e t$ al., 1975a)) or direct (L-CBF (Gamache et al., 1975b)) measurements of blood flow-that is, CBF in survivors varies in a range slightly above or slightly below control levels while under the influence of vasopressors. On the other hand, CBF in non-survivors at this same time initially returns to control levels, only to hover at subnormal levels soon thereafter, despite maintenance of pre-insult arterial gas tension, $\mathrm{pH}$, and blood pressure. The present study, through a continuous recording of blood flow in the same animal, thus complements and extends the validity of the impressions gained from the antipyrine studies, where only a single determination of blood flow for a given instant was possible because of the necessity to sacrifice the animal.

The voltage impression of blood flow in nonsurvivors does differ slightly in one respect from the L-CBF findings. The present voltage values after 90 minutes of recovery suggest that $\mathrm{CBF}$ gradually decreases to (or even slightly exceeds) the levels observed during hypotension, contrary to the L-CBF findings, where blood flow was generally lowest at five minutes of hypotension and moderately decreased (between 50 $70 \%$ of control) during recovery of depressed animals (Gamache et al., 1975b). The present voltage findings seem erroneous in the direction of underestimating flow for two reasons: (1) Bulging of the cortex (observed 60-240 minutes into recovery) automatically changed the position of the flow-probe tip. While efforts were made to readjust the probe tip to a depth of $3 \mathrm{~mm}$, this proved very difficult in swollen tissue.
Thus, the probe tip may have bordered or even entered subcortical white matter. (2) The presence of bulging cortex around the probe tip in three non-survivors probably caused tissue damage (associated with a frank, small haemorrhage in one animal (Table)), altering the geometry of the tissue-probe relationship required for ideal recording (Grayson, 1952) of thermal conductivity, and falsely elevating voltage. The variable amount of tissue fluid (from animal to animal) which invariably collected around the probe tip also exerted a similar effect.

In brief, then, a thermoelectric device for measuring blood flow is simple to use and indeed reflects the general qualitative changes in blood flow to an organ under an investigator's desired conditions. This device is especially suitable for recording dynamic and continuous changes in blood flow. However, considering the sources of error introduced by changes in body temperature, changes in probe position secondary to organ movements (as from mechanical ventilation), and changes in tissue integrity associated with the experimental insult-for example, brain swelling - and compounded by the presence of a foreign body (metal probe), one is cautioned against using the thermoelectric device for establishing more than just qualitative-that is, quantitative - determinations of the dynamics of cerebral blood flow.

The authors are indebted to Dr R. E. Myers, Laboratory of Perinatal Physiology, NINDS, for his review of neuropathological specimens.

\section{REFERENCES}

Carter, L., and Atkinson, J. R. (1973). Cortical blood flow in controlled hypotension as measured by thermal diffusion. Journal of Neurology, Neurosurgery, and Psychiatry, 36, 906-913.

Gamache, F. W., Dold, G., and Myers, R. E. (1975a). Changes in cortical impedance and EEG activity induced by profound systemic hypotension. American Journal of Physiology, 228 (6), 1914-1920.

Gamache, F. W., Myers, R. E., and Monell, E. (1975b). Changes in L-CBF following profound hypotension. Journal of Neurosurgery, 44.

Gibbs, F. A. (1933). A thermoelectric blood flow recorder in the form of a needle. Proceedings of the Society of Experimental Biology and Medicine, 31, 141-146.

Grayson, J. (1952). Internal calorimetry in the determination of thermal conductivity and blood flow. Journal of Physiology, 118, 54-72. 
Norcross, N. (1938). Intracerebral blood flow: experimental study. Archives of Neurology and Psychiatry, 40, 291-299. Reivich, M. (1972). Regional cerebral blood flow in physiological and pathophysiological states. Progress in Brain Research, 35, 191-243.
Sokoloff, L. (1961). Local cerebral circulation at rest and during altered cerebral activity induced by anesthesia or visual stimulation. In The Regional Chemistry, Physiology, and Pharmacology of the Nervous System, pp. 107-117. Edited by S. S. Kety and J. Elkers. Pergamon: Oxford. 